\title{
Fabrication, Characterization, and Functionalization of Single-Walled Carbon Nanotube Conjugated with Tamoxifen and Its Anticancer Potential against Human Breast Cancer Cells
}

\author{
Arshin Oskoueian, ${ }^{1}$ Khamirul Amin Matori $\mathbb{D}^{1,},{ }^{1,2}$ Saadi Bayat $\mathbb{D},{ }^{3,4}$ \\ Ehsan Oskoueian $\mathbb{D}^{5,6}{ }^{5}$ Farhad Ostovan $\mathbb{D}^{7}{ }^{7}$ and Meysam Toozandehjani ${ }^{1}$ \\ ${ }^{1}$ Materials Synthesis and Characterization Laboratory, Institute of Advanced Technology, Universiti Putra Malaysia (UPM), \\ 43400 Serdang, Selangor, Malaysia \\ ${ }^{2}$ Department of Physics, Faculty of Science, Universiti Putra Malaysia (UPM), 43400 Serdang, Selangor, Malaysia \\ ${ }^{3}$ La Trobe Institute for Molecular Science (LIMS), La Trobe University, Melbourne, VIC 3086, Australia \\ ${ }^{4}$ Department of Chemistry, Faculty of Science, Universiti Putra Malaysia (UPM), 43400 Serdang, Selangor, Malaysia \\ ${ }^{5}$ Faculty of Biotechnology and Biomolecular Sciences, Universiti Putra Malaysia (UPM), 43400 Serdang, Selangor, Malaysia \\ ${ }^{6}$ Mashhad Branch, Agricultural Biotechnology Research Institute of Iran (ABRII), Agricultural Research, Education, \\ and Extension Organization (AREEO), Mashhad, Iran \\ ${ }^{7}$ Department of Material Science and Engineering, Islamic Azad University, Bandar Abbas Branch, Bandar Abbas, Iran
}

Correspondence should be addressed to Khamirul Amin Matori; khamirul@upm.edu.my

Received 23 September 2017; Revised 10 December 2017; Accepted 17 December 2017; Published 6 February 2018

Academic Editor: Zafar Iqbal

Copyright (C) 2018 Arshin Oskoueian et al. This is an open access article distributed under the Creative Commons Attribution License, which permits unrestricted use, distribution, and reproduction in any medium, provided the original work is properly cited.

In this experiment, we aimed to fabricate SWCNT conjugated with tamoxifen and evaluated its anticancer potential against human breast cancer cells (MCF-7). The results showed that SWCNT was synthetized successfully using chemical vapor deposition (CVD) method. The results of Raman spectroscopy, SEM, and TEM analyses confirmed the synthesis of highly pure SWCNT. The functionalization of SWCNT was performed by oxidizing of SWCNT, attachment of polyethylene glycol (PEG) to oxidized SWCNT, and attachment of azelaic acid to the polyethylene glycol group. As a result, the SWCNT with free functional carboxylic acid and hydroxyl groups (SWCNT-PEG) was developed. The SWCNT-PEG was then conjugated with tamoxifen (SWCNT-PEG-TAM). The FT-IR together with NMR results confirmed the conjugation of tamoxifen to functionalized SWCNT (SWCNT-PEG-TAM). The cytotoxic concentrations $\left(\mathrm{CC}_{50}\right.$ ) of SWCNT-PEG, tamoxifen, and SWCNT-PEG-TAM were $>100,12.67 \pm 2.69$, and 5.49 \pm 1.34 $\mu \mathrm{g} / \mathrm{ml}$, respectively. Linking tamoxifen to functionalized SWCNT enhanced the cytotoxic action of tamoxifen against breast cancer cells up to 2.3 times. The results of the morphological examination and caspase- 3 activity confirmed the higher cytotoxic action of SWCNT-PEG-TAM as compared to free tamoxifen. The results obtained in this study indicated that this delivery system enhanced the therapeutic effects and anticancer potential of tamoxifen against human breast cancer cells.

\section{Introduction}

The breast cancer is the top leading cause of cancer-related death among female worldwide. The surveys revealed that higher incidences of breast cancer are found in the developed countries as compared to the developing countries. The available reports indicated that populations of 1.7 million cases were diagnosed and 521,900 deaths occurred globally in 2012 [1]. Although the number of people diagnosed with breast cancer is increasing annually, the recent developments in the treatment and diagnosis could hopefully decrease the number of deaths. The drug delivery through attachment of the anticancer molecule to a carrier vehicle opened a new era in cancer treatment strategies. This approach not only resulted in enhanced efficacy of the drug but also minimized drug toxicity to the healthy tissues and organs [2]. 
In the last decade, various nanoscale vectors for the delivery of drugs have been developed such as dendrimers, liposomes, micelles, silica nanoparticles, emulsions, polymers, and quantum dots. However, among these vectors, singlewall carbon nanotubes (SWCNTs) appeared to be promising for the delivery of drugs as soon as the SWCNTs are capable of penetrating into cells. Moreover, they are able to accept multiple functionalizations to increase the drug loading on their structure and their stability and long circulation time in the body [2]. The SWCNTs are made of graphene sheets rolled into a seamless cylinder with open ends where this structure provides a high aspect ratio with the diameter size of nanometer and length of several micrometers [3]. Various studies revealed that the SWCNTs could effectively transport the bioactive molecules such as drugs, peptides, and proteins into cells [4]. In fact, their exclusive physical, chemical, and mechanical properties have attracted the great interest for drug delivery purposes [5]. The metal contamination during synthesis, biocompatibility, and hydrophobicity are major obstacles which limited the biomedical applications of SWCNTs. However, recent progress in synthesis, purification of SWCNTs, surface engineering, and functionalization facilitated the development of SWCNT-based drug delivery systems with high biocompatibility, less hydrophobicity, and higher loading capacity and therapeutic efficacy [4].

The therapeutic efficacy of anticancer drug has been shown to be dependent on the physicochemical properties of CNTs and their functionalization process. For instance, a study conducted by Yang et al. [6] indicated that functionalized CNTs loaded with gemcitabine improved the cytotoxicity of gemcitabine against human pancreatic cancer cells (SW1990 and BxPC-3 cells). Similarly, the paclitaxel is also an anticancer drug with poor water solubility, low blood circulation time. The conjugation of paclitaxel to functionalized SWCNT through branched polyethylene glycol chains prolonged the circulation time and improved the therapeutic efficacy of drug against human breast cancer [7] and cervical cancer cells [8]. In another study, a gold nanoparticle conjugated with tamoxifen (TAM) showed the enhanced tamoxifen efficacy about 2.7 times more than free tamoxifen in breast cancer cell lines (MCF-7 and MDA-MB 231) [9]. The tamoxifen as an anticancer drug has been extensively applied to treat the breast cancer and it acts through binding to the estrogen receptor family.

In the present study, highly pure SWCNT was synthetized and functionalized using polyethylene glycol (PEG). This drug vehicle (SWCNT-PEG) was then conjugated to an anticancer drug, tamoxifen (SWCNT-PEG-TAM). Further, the functionalized SWCNT conjugated with tamoxifen was characterized by using spectroscopic techniques including FTIR and NMR spectroscopy. Then, the anticancer potential of SWCNT-PEG-TAM was determined against human breast cancer cell line (MCF-7).

\section{Material and Methods}

2.1. Materials and Reagents. The silicon dioxide, cobalt acetate, iron acetate, absolute ethanol, nitric acid, hydrofluoric acid, n, $\mathrm{n}^{\prime}$-diisopropylcarbodiimide (DIC), 4-dimethylaminopyridine (DMAP), dimethylformamide (DMF), DCM, and all the reagents for cell culture were purchased from Sigma Aldrich (Sigma Aldrich, St. Louis, MO, USA). The gases including argon and carbon dioxide were provided by the MOX Company (MOX, Sdn Bhd, Malaysia). The reagents that have not been listed here were purchased from Merck (Merck, Darmstadt, Germany).

2.2. Fabrication of SWCNT. The metal catalyst supported with $\mathrm{SiO}_{2}$ was prepared according to Zhao et al. [10] and Maruyama et al. [11] with slight modifications. Briefly, 1 gram of cobalt acetate $\left(\left(\mathrm{CH}_{3} \mathrm{CO}_{2}\right)_{2} \mathrm{Co} \cdot 4 \mathrm{H}_{2} \mathrm{O}\right)$ and 1 gram of iron acetate $\left(\mathrm{CH}_{3} \mathrm{CO}_{2}\right)_{2} \mathrm{Fe}$ were dissolved in $40 \mathrm{ml}$ of ethanol and stirred for 30 minutes. Then, 1 gram of $\mathrm{SiO}_{2}$ was added to the solution, mixed, and then sonicated (LabSonic, B. Braun, Germany) with the pulses of $0.3 \mathrm{~s}$ at 50 watts for 20 minutes. Finally, it was dried in an oven at $80^{\circ} \mathrm{C}$ for 24 hours. The resultant fine powder gently scratched and placed into the alumina boat and transferred into the tube of CVD. Above $200 \mathrm{sccm}$ Argon flow was maintained while quartz tube was heated up to the favored reaction temperature. As the boat had been heated to the desired temperature $\left(850^{\circ} \mathrm{C}\right)$ within roughly 90 minutes, argon gas was evacuated and the vacuum pomp is kept on and alcohol delivered from a reservoir in room temperature for normally 20 minutes. Through controlling the temperature of reservoir and vacuum pomp, the alcohol vapor pressure was maintained at 10 Tor. After 20 minutes, rotary pomp was switched off and $200 \mathrm{sccm}$ argon was supplied to the tube till the furnaces temperature reaches the room temperature. The blackened sample on the boat after cooling down was collected for purification.

2.3. Purification and Characterization of SWCNT. The SWCNT fabricated in this study may contain carbonaceous contaminations and metal particles. The carbonaceous impurities usually contain amorphous carbon, fullerenes, and carbon nanoparticles [12]. To remove these impurities, twostep purification is employed as described by Liu et al. [13] with slight modifications. The synthesized SWCNT was mixed with concentrated nitric acid and sonicated (LabSonic, B. Braun, Germany) with the pulses of $0.3 \mathrm{~s}$ at 50 watts for 10 minutes. The mixture was refluxed at $120^{\circ} \mathrm{C}$ for $10 \mathrm{~h}$. The SWCNT was filtered and washed with distilled water repeatedly to reach neutral $\mathrm{pH}$. After nitric acid treatment, the residual sample is still contaminated with $\mathrm{SiO}_{2}$. The hydrofluoric acid treatment is established to remove the $\mathrm{SiO}_{2}$ from SWCNT. The mixture of concentrated hydrofluoric acid and synthesized SWCNT was stirred for 3-4 hours at room temperature. Then, the SWCNT was filtered and washed with distilled water repeatedly to reach neutral $\mathrm{pH}$. Finally the SWCNT was lyophilized and transferred into an amber container kept in cool and dry place.

The Raman spectrometry analysis was conducted in the back-scattering geometry using a single monochromator with a microscope (LabRam HORIBA Jobin Yvon, Edison, $\mathrm{NJ})$. The continuous wave second harmonic of an Nd:YAG laser at $2.31 \mathrm{eV}(532 \mathrm{~nm})$ was applied for excitement in the SWCNT. The Raman spectra were obtained from different locations of the SWCNT. The scanning electron microscopy 


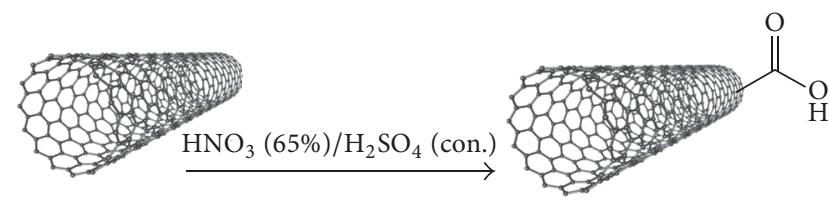

FIGURE 1: Oxidation of single-wall carbon nanotube surface.

(SEM) was performed using a JEOL-6-400 (Japan) Scanning Microscope. The synthesized carbon nanotube was placed on a conductive carbon tape and then coated with a thin gold layer for clear visualization. The transmission electron microscopy (TEM) was conducted using a JEOL JEM-2010 (Japan) electron microscope. The synthesized carbon nanotube was dispersed in ethanol using an ultrasonic (Hielscher, Germany) and dropped on a carbon-coated copper grid and viewed at an acceleration voltage of $200 \mathrm{kV}$.

\subsection{Functionalization of SWCNT}

2.4.1. Oxidation of SWCNT. Tsang et al. [14] reported the liquid-phase oxidation of carbon nanotubes in $\mathrm{HNO}_{3}$. Various oxidants have been shown to react with carbon nanotubes. The oxygen containing acids including $\mathrm{HNO}_{3}, \mathrm{HNO}_{3}$ $+\mathrm{H}_{2} \mathrm{SO}_{4}, \mathrm{HClO}_{4}, \mathrm{H}_{2} \mathrm{SO}_{4}+\mathrm{K}_{2} \mathrm{Cr}_{2} \mathrm{O}_{7}$, and $\mathrm{H}_{2} \mathrm{SO}_{4}+\mathrm{KMnO}_{4}$, remain as the main class of oxidants that have been reported in the literature [15].

In this work, SWCNT was oxidized by using strong oxidant which was a mixture of $\mathrm{HNO}_{3} / \mathrm{H}_{2} \mathrm{SO}_{4}(3: 1)$. The mixture was stirred at room temperature for an overnight. The oxidized SWCNT was filtered using sinter glass and then washed with deionized water to reach $\mathrm{pH}=5-6$. The oxidized SWCNT was dried using high vacuum oven at $40^{\circ} \mathrm{C}$ for an overnight (Figure 1).

The oxidized SWCNT was characterized using FT-IR to prove oxidation process by observing carboxylic acid group on SWCNT. FT-IR spectroscopy well proved that SWCNT was oxidized very well with the good yield.

2.4.2. Attachment of Polyethylene Glycol to Oxidized SWCNT. The solubility of carbon nanotube is the main concern for its biological application. In fact, fully dissolving of SWCNT is difficult; however, attaching of some hydrophilic groups could help to increase the solubility. To achieve this purpose, polyethylene glycol $(\mathrm{FW}=1000)$ was utilized. From chemistry point of view, first, carboxylic acid group on the surface of SWCNT was activated by using $N, N^{\prime}$ diisopropylcarbodiimide (DIC) and 4-dimethylamino-pyridine (DMAP) [16]. Single-wall carbon nanotube was dissolved in DMF (N,N-dimethylformamide); then DIC and DMAP were added to the reaction mixture. After $5 \mathrm{~min}$, polyethylene glycol was added to the reaction mixture. The mixture was serried overnight at room temperature. Then, the mixture was filtered and the product was washed with two portions of DMF $(2 \times 50 \mathrm{~mL})$ to remove excess of reagents.
The product was washed with two portions $(2 \times 50 \mathrm{~mL})$ of dichloromethane for removing impurities and quick drying of product (Figure 2).

2.4.3. Attachment of Azelaic Acid to the Polyethylene Glycol Group. In order to attach the polyethylene glycol group to the oxidized SWCNT, a novel technique of synthesis was applied in this work. The terminal hydroxyl group of polyethylene glycol was reacted with a carboxylic acid (azelaic acid) to prepare ester in one side and having free carboxylic acid in another side. Thus, attaching of the hydroxyl group to carboxylic group of azelaic acid was performed using DIC/DMAP methodology (Figure 3). As a result, free functional groups (carboxylic acid and hydroxyl) are produced which were used to attach the bioactive molecules [17].

Modified SWCNT with polyethylene glycol (1gr) was dispersed to the DMF/DCM $(1: 1,10 \mathrm{~mL})$, and a mixture of azelaic acid (2 gr) and DMAP (1.30 gr) and DIC (1.4 gr) in $5 \mathrm{~mL}$ DMF was added to the modified SWCNT suspension. The reaction mixture was stirred overnight at ambient temperature. Then, the reaction was filtered off and washed properly with DMF/DCM $(1: 1,4 * 10 \mathrm{~mL})$. The solid form of modified SWCNT was dried in an oven $\left(40^{\circ} \mathrm{C}\right)$.

2.4.4. Preparation of N-Desmethyltamoxifen. Tamoxifen has an amine functional group that was blocked by two methyl groups which are tert-amines. Before reacting free carboxylic acid with tamoxifen, one methyl group should be removed from tert-amine. For removing methyl group, 1-chloroethyl chloroformate was employed in dichloromethane at room temperature (Figure 4 ).

A solution of tamoxifen $(1.2 \mathrm{~g}, 3.23 \mathrm{mmol})$ in anhydrous dichloroethane $(40 \mathrm{~mL})$ was treated with $\alpha$-chloroethyl chloroformate $(1.4 \mathrm{~mL}, 12.96 \mathrm{mmol})$ at $0^{\circ} \mathrm{C}$. After $15 \mathrm{~min}$ at $0^{\circ} \mathrm{C}$, the reaction was refluxed for $6 \mathrm{~h}$. The progress of the reaction was monitored by TLC (EtOAc: n-Hex 1:1). The solvent was evaporated under vacuum to obtain yellow viscous oil. The recrystallization by EtOH and $\mathrm{Et} 2 \mathrm{O}$ gave the purified $\mathrm{N}$ desmethyltamoxifen $(0.99 \mathrm{~g}, 94 \%)$.

2.4.5. Chemically Attachment of Tamoxifen on SWCNT. The produced $\mathrm{N}$-desmethyltamoxifen was reacted with attached free carboxylic acid on SWCNT. For this purpose, the reaction mixture, DIC/DMAP in DMF/DCM as solvents in the presence of a base which is diisopropylethylamine (DIEA) at room temperature, was stirred overnight (Figure 5). Then, the reaction mixture was filtered and washed with $\mathrm{N}, \mathrm{N}$ dimethylformamide and dichloromethane to remove impurities.

2.5. Tamoxifen Content Analysis. The tamoxifen content of functionalized SWCNT (loading efficiency) was determined as described by Sahana et al. [18]. Briefly, to extract the tamoxifen from SWCNT-PE the SWCNT-PE-TAM (5 mg) was dispersed in $2 \mathrm{ml}$ of $0.01 \mathrm{M}$ phosphate buffered saline ( $\mathrm{pH} 7.4$ ) containing $2.5 \% \mathrm{w} / \mathrm{v}$ sodium dodecyl sulphate (SDS) and the mixture was shaken for $3 \mathrm{~h}$ in shaking incubator at $37^{\circ} \mathrm{C}$. The mixture was then centrifuged at $3000 \times \mathrm{g}$ for $2 \mathrm{~min}$. The supernatant $(1 \mathrm{ml})$ was transferred to a cuvette and 


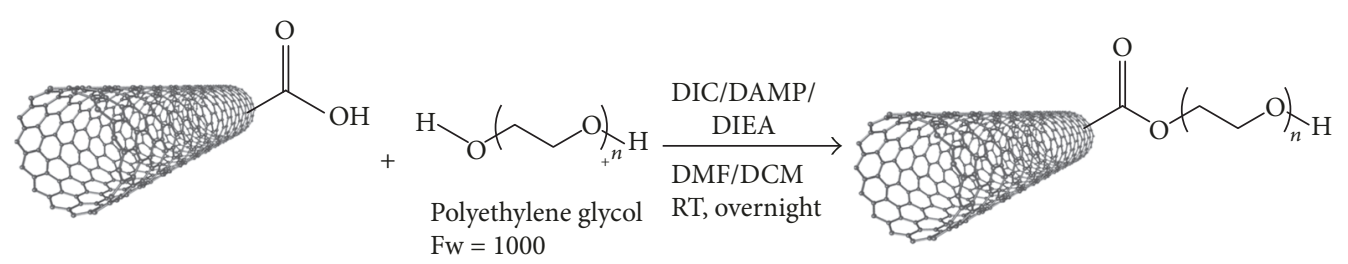

FIGURE 2: Reaction of polyethylene glycol with oxidized SWCNT.

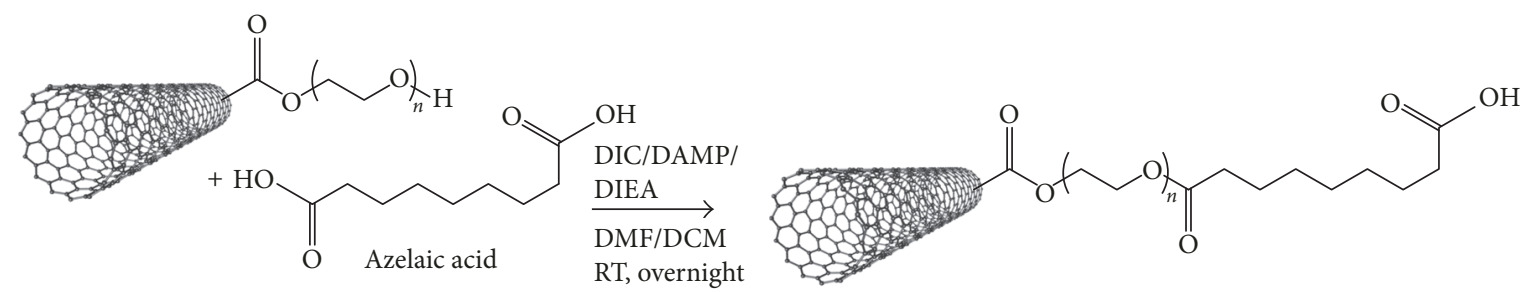

FIGURE 3: Reaction of azelaic acid with the polyethylene glycol on the surface of the SWCNT.

the absorbance was recorded using spectrophotometer at $275 \mathrm{~nm}$. The drug loading efficiency was determined from the calibration curve prepared earlier using the following formula:

$$
\begin{aligned}
& \text { Percentage of tamoxifen loading efficiency } \\
& \qquad=\left[\frac{(\text { weight of tamoxifen in } 1 \mathrm{mg} \text { of product } \times \text { total weight of formulation })}{\text { (total tamoxifen taken for formulation of a particular batch })}\right] \times 100 \text {. }
\end{aligned}
$$

2.6. Cytotoxicity Assay. The human breast cancer cells (MCF7 ATCC: HTB22) were purchased from American Type Culture Collection (ATCC). The cells were grown using Dulbecco's Modified Eagle Medium (DMEM) supplemented with $10 \%$ fetal bovine serum in a $\mathrm{T}-75 \mathrm{~cm}^{2}$ culture flask and kept at $37^{\circ} \mathrm{C}$ in $5 \% \mathrm{CO}_{2}$ humidified incubator (Thermo Electron Corporation, Waltham, MA, USA) [19]. The antibiotic penicillin $(100 \mathrm{U} / \mathrm{ml})$ and streptomycin $(100 \mu \mathrm{g} / \mathrm{ml})$ (Euroclone, Italy) were provided to avoid bacterial contamination. The stock suspensions of SWCNT-PE, tamoxifen, and SWCNT-PE-tamoxifen were prepared in DMEM. By considering the loading efficiency of tamoxifen in SWCNTPE-tamoxifen, equal tamoxifen concentrations in stock suspension were prepared from tamoxifen and SWCNT-PEtamoxifen. Briefly, the confluent cells were seeded in 96well microtiter plates (Nunc, Denmark) at a density of 1 $\times 10^{5}$ cells $/ \mathrm{ml}$ in $100 \mu \mathrm{l}$ DMEM containing $10 \%$ FBS for $24 \mathrm{~h}$. Then, the media were removed and fresh media containing different concentrations of SWCNT-PE, tamoxifen, and SWCNT-PE-tamoxifen $(0-100 \mu \mathrm{g} / \mathrm{ml})$ were added. Plates were incubated for $24 \mathrm{~h}$. Cells in the same media without any of SWCNT-PE, tamoxifen, and SWCNT-PE-tamoxifen were included as negative control. At the end of incubation period 3-(4,5-Dimethylthiazol-2-yl)-2,5-Diphenyltetrazolium Bromide (MTT) solution $(10 \mu \mathrm{l}$, at the concentration of $5 \mathrm{mg} / \mathrm{ml})$ prepared in phosphate buffered saline (PBS) was added to each of wells and the plates were incubated in an incubator $\left(37^{\circ} \mathrm{C}, 5 \% \mathrm{CO}_{2}\right)$ for extra $4 \mathrm{~h}$. The medium was removed and $200 \mu \mathrm{l}$ dimethyl sulfoxide (DMSO) was added to each well. The plates were shaken for $5 \mathrm{~min}$ and the absorbance was recorded at $570 \mathrm{~nm}$ using a microplate reader (VersaMax, Molecular Devices, Sunnyvale, CA) [20]. The percentage of cell viability was calculated by using the following formula:

$$
\text { Cell viability }(\%)=\left[\frac{(\text { ODsample })}{(\text { ODcontrol })}\right] \times 100 \text {. }
$$

The concentration required to reduce cell growth or viability by $50 \%$ was reported as $50 \%$ cytotoxic concentration (CC50).

2.7. Morphological Examination of Cells. The human breast cancer cells (MCF-7 cell line) were seeded at a density of $3 \times 10^{5}$ cells per well in 6-well plates and allowed to adhere overnight. After $24 \mathrm{~h}$ incubation, the media were removed and fresh media containing $25 \mu \mathrm{g} / \mathrm{ml}$ of SWCNTPE, tamoxifen, and SWCNT-PE-tamoxifen were added. The treated cells were then incubated at $37^{\circ} \mathrm{C}$ in $5 \% \mathrm{CO}_{2}$ for $24 \mathrm{~h}$. Morphological changes were examined after $24 \mathrm{~h}$ incubation, and the cells were photographed using an inverted microscope (Nikon, Tokyo, Japan) [21].

2.8. Caspase-3 Activity Assay. The caspase-3 activity was determined in MDBK cells using caspase-3 colorimetric assay kit (Abcam, ab39401, Cambridge, UK) according to the 
<smiles>CC/C(=C(\c1ccccc1)c1ccc(OCCN(C)C)cc1)c1ccccc1</smiles>

Tamoxifen

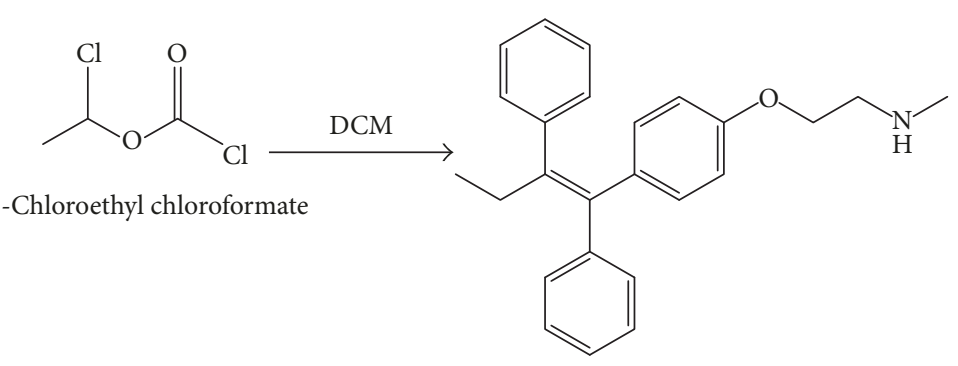

(4-hydroxy-N-desmethyl-tamoxifen)

Figure 4: Demethylation of tamoxifen.

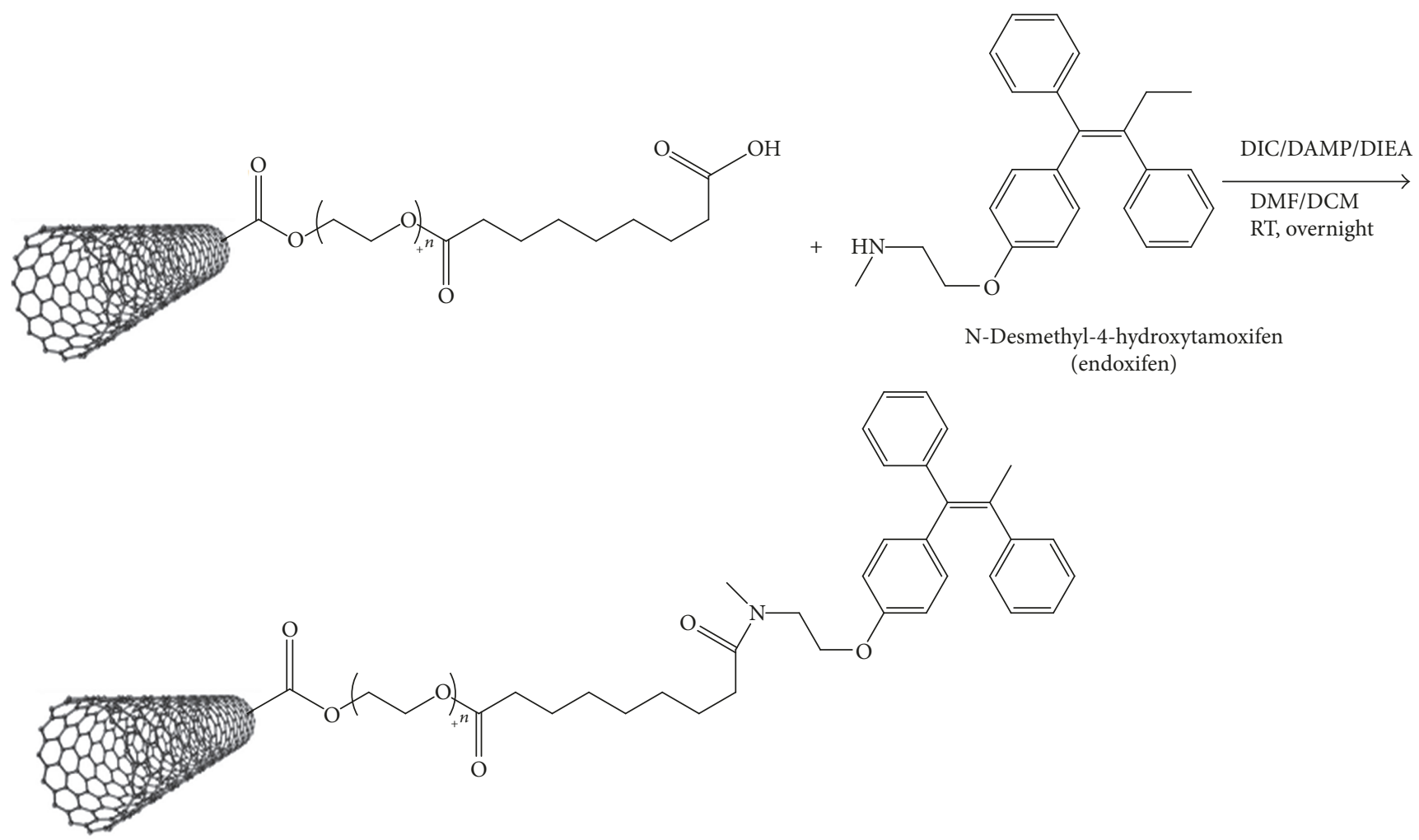

FIGURE 5: Chemically attachment of N-desmethyltamoxifen to the functionalized SWCNT.

instruction provided by the kit. Briefly, MDBK cells were cultured and treated with isolated phorbol esters at the $\mathrm{CC}_{50}$ concentration for $24 \mathrm{~h}$. Then, the cells were trypsinized, washed with PBS, and lysed with lysis buffer and sonicated as mentioned in the protein expression analyses section. The cell homogenate centrifuged for $10 \mathrm{~min}$ at $15000 \mathrm{rpm}$ and the supernatant was used for colorimetric reaction and the absorbance value was recorded at $405 \mathrm{~nm}$. The absorbance values were normalized to the protein level of the samples.

2.9. Statistical Analyses. Cytotoxicity results were subjected to statistical analysis using the GLM procedure [22] employing a complete randomized design following the model: $\mathrm{Yi}=$ $\mu+\mathrm{Ti}+\mathrm{ei}$, where $\mu$ is the mean value, $\mathrm{Ti}$ is the treatment effect, and ei is the experimental error, respectively. Means were compared using Duncan's New Multiple Range test. Differences were considered significant at $p \leq 0.05$. All measurements were carried out in triplicate.

\section{Results and Discussion}

3.1. Characteristics of Fabricated SWCNT. The Raman spectrum of the unpurified and purified SWCNT is presented in Figures 6(a) and 6(b), respectively. The low frequency regions at the initial part of the spectrum (Figures 6(a) and 6(b)) belong to the radial breathing mode (RBM) bands. The peak which appeared at $1375 \mathrm{~cm}^{-1}$ corresponded to disorder band (D-band). The peaks at $1582 \mathrm{~cm}^{-1}$ and $2720 \mathrm{~cm}^{-1}$ were attributed to graphene and graphite bands (G- and $G^{\prime}$-band), 


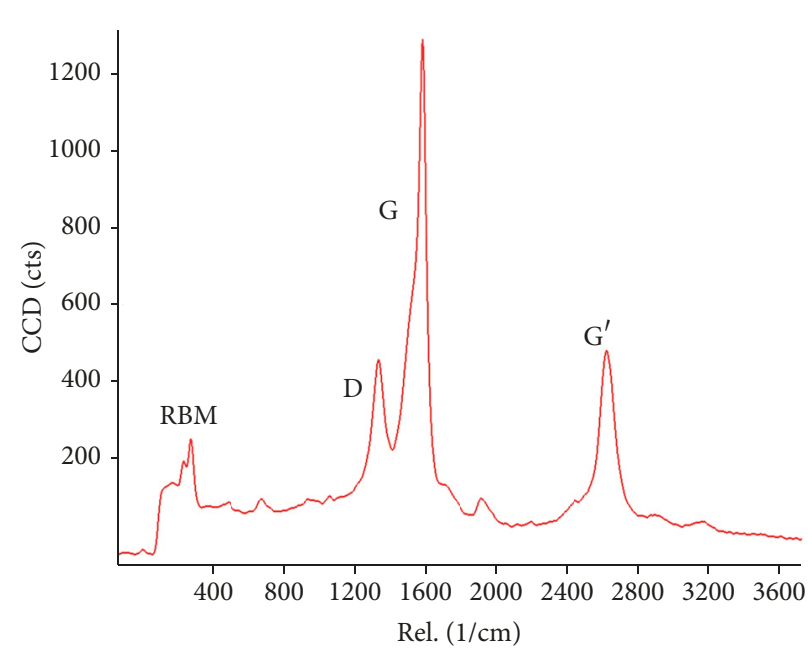

(a)

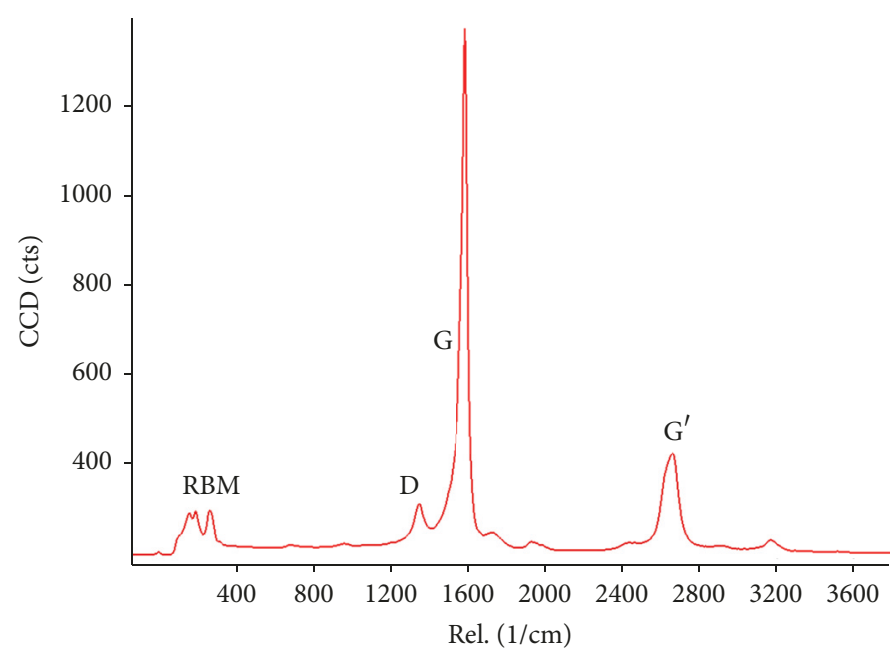

(b)

FIGURE 6: Raman spectroscopy of unpurified SWCNT (a) and purified SWCNT (b).

respectively. The D-band indicated the presence of defective materials, while G- and $\mathrm{G}^{\prime}$-bands showed the well-ordered graphite, respectively. The results illustrated that purification of SWCNT led to decrease in D-band indicating the fabrication of high quality and pure SWCNT.

Figures 7(a) and 7(b) illustrated the images from unpurified SWCNT taken by SEM and TEM, respectively. The SEM image showed the abundance of fiber-like carbon nanotube networks with several micrometers in length. These carbon filaments were uniform and possessed consistent appearance. The SEM and TEM images confirmed the presence of amorphous carbon and catalyst residue at the surface of unpurified SWCNT.

Figures 8(a) and 8(b) showed the SEM and TEM images of purified SWCNT, respectively. As observed, almost all the carbonaceous impurities and metal catalyst particles have been removed from carbon filaments. Application of two steps of purification leads to the synthesis of highly pure SWCNT. The diameter of SWCNT was found to be in the range of 0.6 to $5 \mathrm{~nm}$ with a mean of $1.9 \mathrm{~nm}$.

3.2. Characterization of Functionalized SWCNT. In this work, SWCNT was oxidized by using strong oxidant containing a mixture of $\mathrm{HNO}_{3}$ and $\mathrm{H}_{2} \mathrm{SO}_{4}(3: 1)$. The oxidized SWCNT was characterized using FT-IR to prove oxidation procedure by observing carboxylic acid group on SWCNT. The FT-IR spectroscopy confirmed the oxidation of SWCNT with the appreciable yield.

The FT-IR analysis was performed in the range 4000$400 \mathrm{~cm}^{-1}$ for the identification of functional group attached to the surface of the SWCNT. The FT-IR spectroscopy has been used extensively in the structural determination of the molecules. FT-IR spectrum in Figure 9 clearly shows that the surface of SWCNT was oxidized to carboxylic acid. In the red color spectrum, the wide peak at $3280 \mathrm{~cm}^{-1}$ could be assigned to the presence of -OH group of carboxylic acid and the peak which appeared at $2939 \mathrm{~cm}^{-1}$ showed the presence of $\mathrm{C}-\mathrm{H}$ bond [23]. The peak which appeared at $1625 \mathrm{~cm}^{-1}$ represented carbonyl group $(\mathrm{C}=\mathrm{O})$ bond, whereas the blue color spectrum belongs to the unfunctionalized SWCNT, and there is no peak in the functional group regions except for $\mathrm{C}$ $\mathrm{C}$ stretch in the fingerprinting region. It was observed that, in the functionalization process, several functional groups such as carboxylic (-COOH), carbonyl (-CO), and hydroxylic ($\mathrm{OH})$ groups were formed on the surface of nanotubes [24].

Solid phase CNMR and HNMR studies were performed to determine the carbon of carbonyl and proton of carboxylic acid made on the surface of SWCNT. Solid phase HNMR analysis of SWCNT (Figure 10) showed the presence of protons in $3.798 \mathrm{ppm}$ which was assigned to the $\mathrm{C}-\mathrm{H}$ bond in the SWCNT. And in the SWCNT upon oxidization by strong oxidant $\left(\mathrm{HNO}_{3} / \mathrm{H}_{2} \mathrm{SO}_{4}\right)$ (Figure 1 ), protons of $\mathrm{C}-\mathrm{H}$ were shifted to upper field area $(4.98 \mathrm{ppm})$. This result was due to the presence of withdrawing electron group which was -COOH. The two peaks which appeared at 10.267 and 11.462 ppm were representative of proton of the attached carboxylic acid group on the surface of carbon nanotube.

CNMR of SWCNT has been shown in Figure 12. The peaks which appeared in range 20-120 ppm could be assigned to aliphatic carbons. Once the SWCNT was oxidized, it could be observed that a peak appeared in $194.72 \mathrm{ppm}$ (Figure 13) which belongs to the carbonyl group $(\mathrm{C}=\mathrm{O})$ of carboxylic acid. CNMR spectra also strongly proved that $-\mathrm{COOH}$ groups attached to the surface of carbon nanotube (Figure 13).

3.3. Attachment of Polyethylene Glycol to Oxidized SWCNT. The FT-IR spectroscopy analysis was performed to confirm the attachment of polyethylene glycol to oxidized SWCNT. According to the spectrum results demonstrated in Figure 14, poly ethylene has been attached to the SWCNT successfully. The broad peak which appeared at $3066 \mathrm{~cm}^{-1}$ could be assigned to the hydroxyl group of polyethylene. Aliphatic C$\mathrm{H}$ stretch appeared at $2872 \mathrm{~cm}^{-1}$. The peak at $1664 \mathrm{~cm}^{-1}$ was assigned to carbonyl $(\mathrm{C}=\mathrm{O})$ group. The peak at $1486 \mathrm{~cm}^{-1}$ 


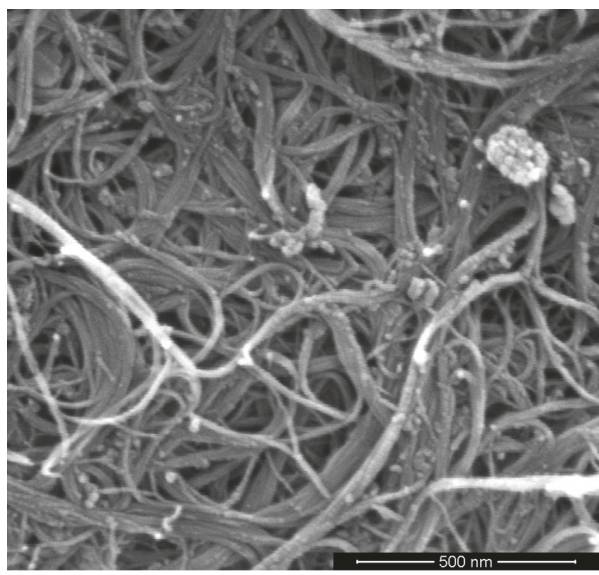

(a)

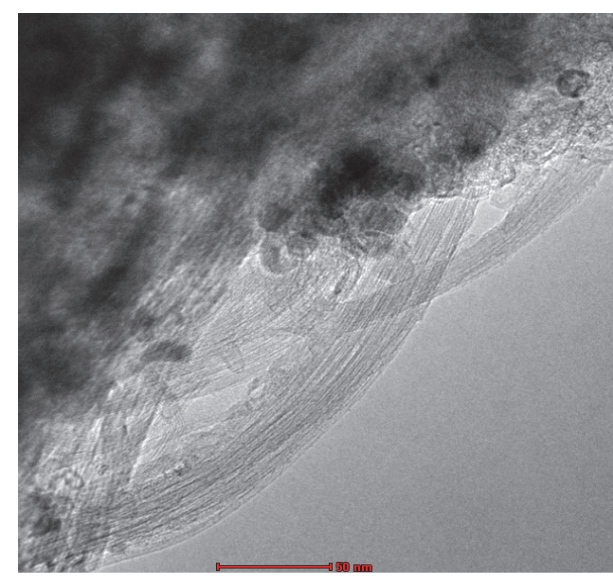

(b)

FIGURE 7: (a) The SEM image of unpurified SWCNT and (b) the TEM image of unpurified SWCNT.

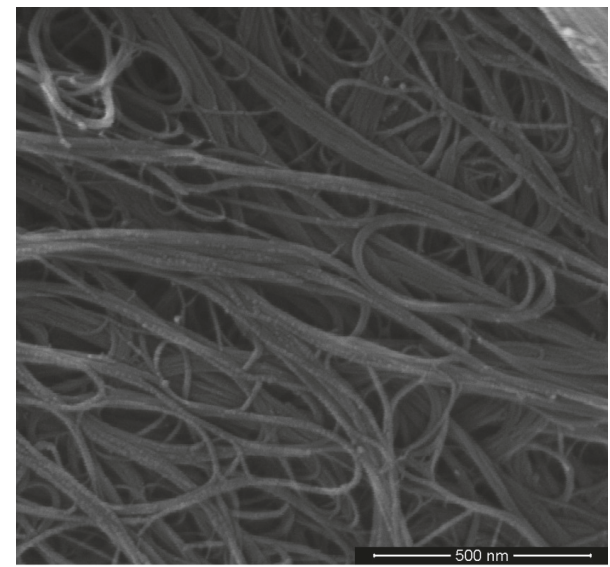

(a)

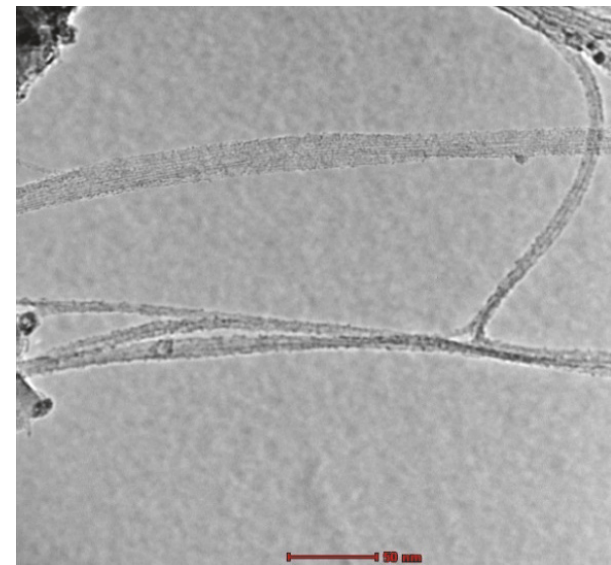

(b)

FIGURE 8: (a) The SEM image of purified SWCNT and (b) the TEM image of purified SWCNT.

indicated $\mathrm{CH}_{2}$ bonding of ethylene monomer. The peak which appeared at $1302 \mathrm{~cm}^{-1}$ could be assigned to the $\mathrm{C}-\mathrm{O}-\mathrm{C}$ stretch, while the peak visible at $1068 \mathrm{~cm}^{-1}$ was identified as C-O stretch.

3.4. Attachment of Azelaic Acid to the Polyethylene Glycol Group. Successful functionalization of SWCNT could be verified using FT-IR spectra shown in Figure 15. The strong bond which appeared at $1517 \mathrm{~cm}^{-1}$ was assigned to the characteristic $\mathrm{C}=\mathrm{O}$ vibrations and confirmed the existence of carbonyl groups of free acids and ester component. A broad band which appeared at around $3139 \mathrm{~cm}^{-1}$ was attributed to the $-\mathrm{COOH}$ group. The bond visible at $2872 \mathrm{~cm}^{-1}$ corresponded to the stretching and bending vibrations of aliphatic $\mathrm{C}-\mathrm{H}$. The bond presented at $1374 \mathrm{~cm}^{-1}$ was the characteristic of C-O stretching. FT-IR spectrum indicated that all reacted functional groups have been attached to the SWCNT.

3.5. Preparation of $\mathrm{N}$-Desmethyltamoxifen. The results of proton NMR analyses for oxidized SWCNT, tamoxifen, and
N-desmethyltamoxifen are shown in Figures 11, 16, and 17, respectively. In Figure 16, the peak which appeared around $2.7 \mathrm{ppm}$ indicated six protons of two methyl groups attached to the tert-amine. As observed in Figure 16, after demethylation, the number of the protons for methyl attached to the amine group was decreased to three. So, this spectrum clearly demonstrated that tamoxifen has been converted to $\mathrm{N}$-desmethyltamoxifen.

3.6. Chemical Attachment of Tamoxifen on SWCNT. NDesmethyltamoxifen was reacted with attached free carboxylic acid (in azelaic acid side) on SWCNT. The FT-IR spectrum data demonstrated that chemically attachment of tamoxifen successfully occurred (Figure 18). The bonds which appeared at 2892 and $2878 \mathrm{~cm}^{-1}$ were attributed to $\mathrm{C}-\mathrm{H}$ stretching of aliphatic and aromatic components. The sharp peaks which appeared at 1665 and $1520 \mathrm{~cm}^{-1}$ were the characteristic of $\mathrm{C}=\mathrm{O}$ functional groups. The sharp peak visible at $1285 \mathrm{~cm}^{-1}$ corresponded to $\mathrm{C}-\mathrm{O}$ groups. In addition, sum peaks observed in the finger print region are corresponding 


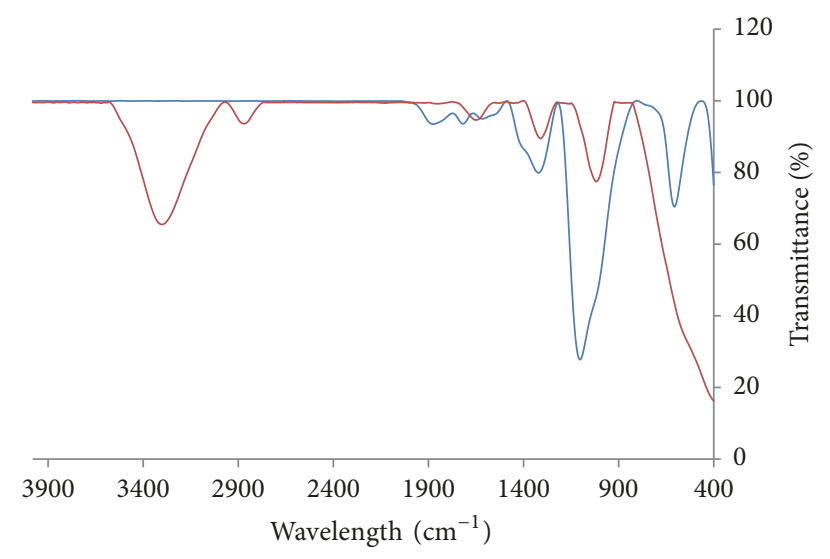

FIGURE 9: The FT-IR analyses of SWCNT: blue color represents SWCNT before oxidation and red color shows SWCNT after oxidation.

NSW, acid $1 \mathrm{H}$

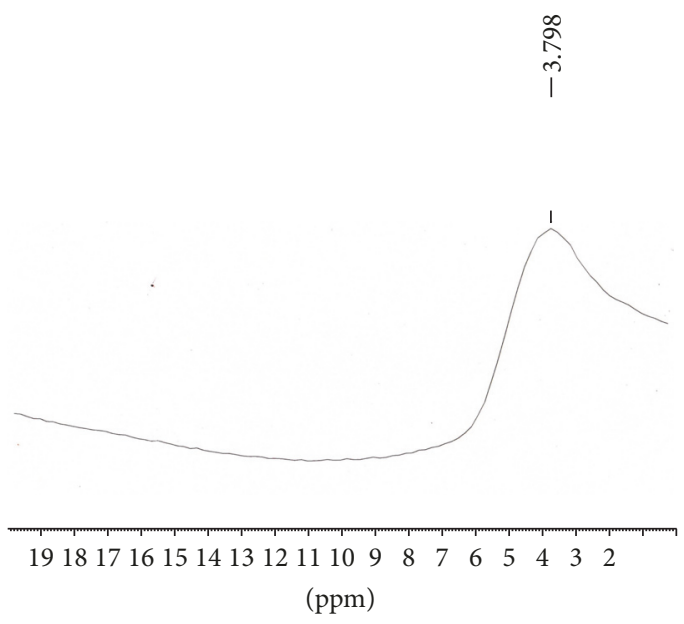

FIGURE 10: HNMR spectra of functionalized SWCNT.

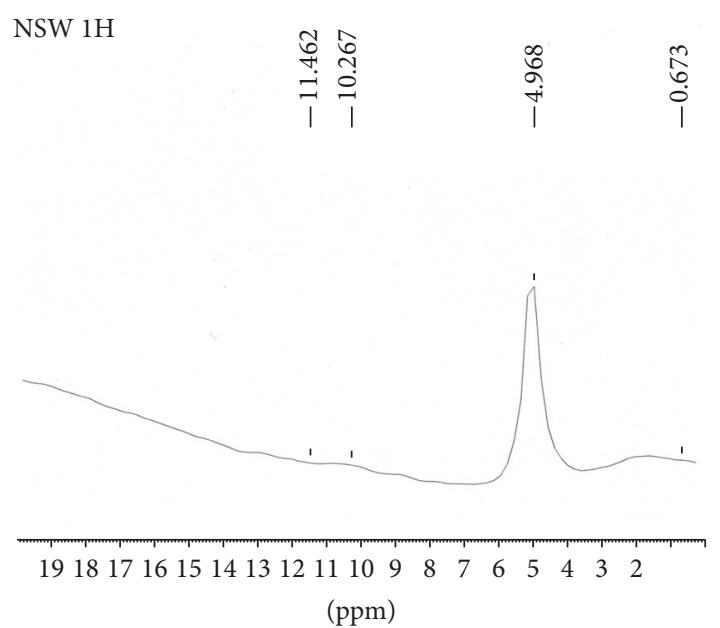

$19181716151413121110 \quad 9 \quad 8 \quad 7 \quad 6 \quad 5 \quad 4 \quad 3 \quad 2$ (ppm)

FIGURE 11: HNMR spectra of oxidized SWCNT.
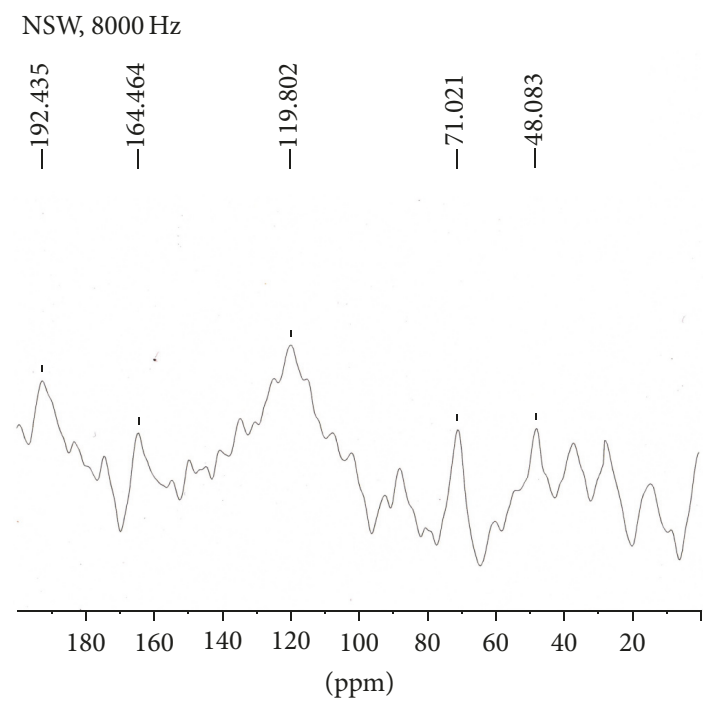

FIGURE 12: Solid phase CNMR of SWCNT.

NSW, acid 13C
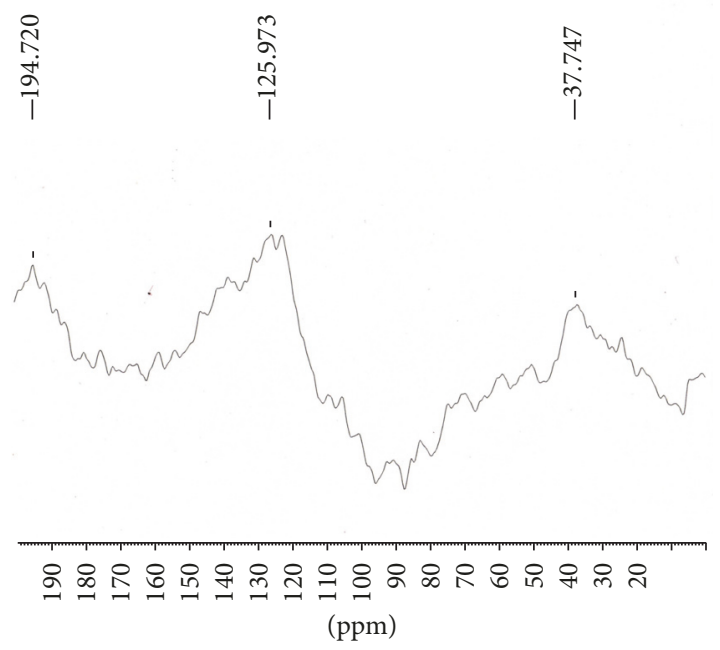

FIGURE 13: Solid phase CNMR of functionalized SWCNT.

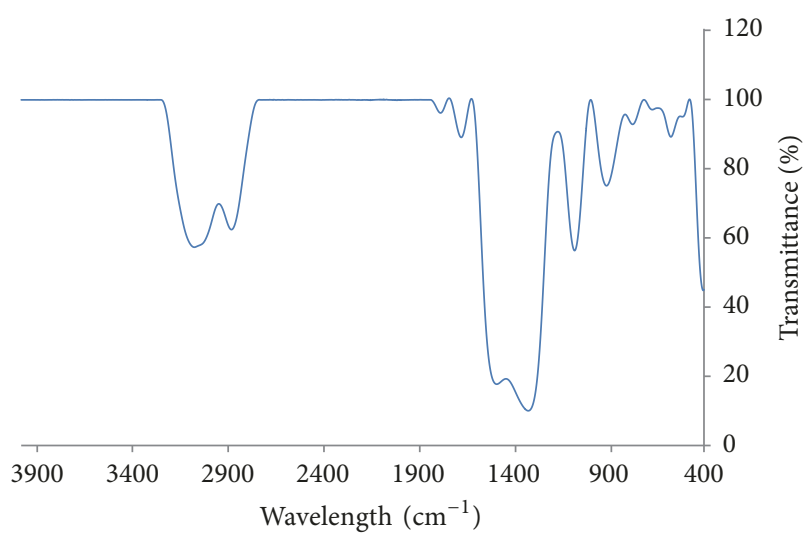

FIGURE 14: FT-IR spectra of the reaction of polyethylene glycol with oxidized SWCNT. 


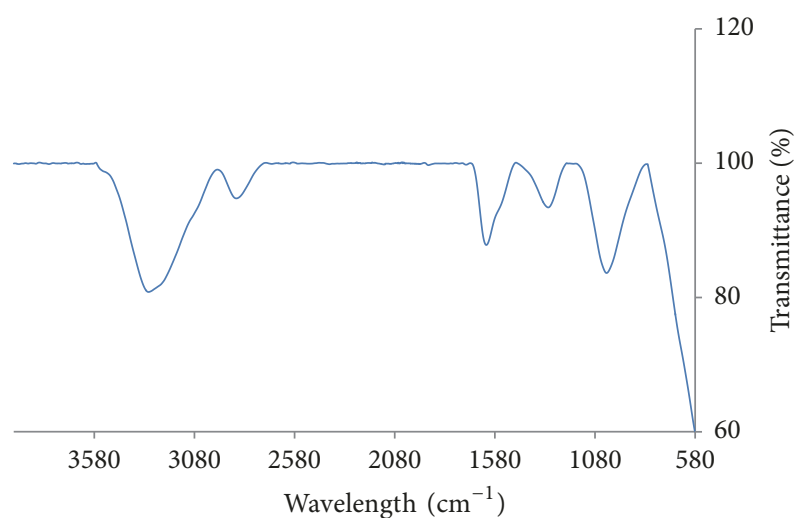

FIGURE 15: The FT-IR spectrum of the attachment of azelaic acid to the polyethylene glycol group.

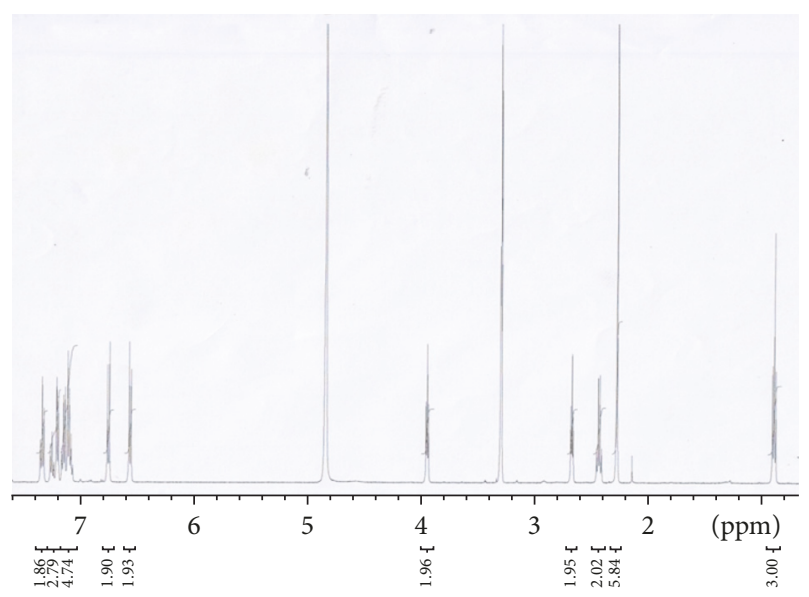

FIGURE 16: HNMR of standard tamoxifen.

to the stretching and bending vibrations of aromatic $\mathrm{C}-\mathrm{H}$ and aliphatic $\mathrm{CH}_{2}$.

3.7. Tamoxifen Content Analysis in SWCNT-PE-TAM. The tamoxifen content of the SWCNT-PEG-TAM is shown in Table 1 . The tamoxifen content analysis showed that SWCNTPEG-TAM complex contained $67 \%$ tamoxifen.

3.8. Cytotoxicity Assay. Figure 19 shows the viability of human breast cancer cells exposed to various concentrations of SWCNT-PEG, tamoxifen, and SWCNT-PEG-TAM ranging from 0 to $100 \mu \mathrm{g} / \mathrm{ml}$ upon $24 \mathrm{~h}$ incubation. The significant $(p<0.05)$ decrease in cell viability with dose-dependent manner was observed in all treatments. The $\mathrm{CC}_{50}$ concentrations are presented in Table 2. The $\mathrm{CC}_{50}$ values appeared in the ascending order SWCNT-PEG $>$ tamoxifen $>$ SWCNTPEG-TAM. The lower $\mathrm{CC}_{50}$ represented the higher cytotoxic action; thus, from this result, it is postulated that linking tamoxifen to functionalized SWCNT enhanced the cytotoxic action of tamoxifen against breast cancer cells. The improved cytotoxic effects of SWCNT-PEG-TAM probably were due to the higher cell penetration of tamoxifen conjugated SWCNTPE. This was probably attributed to the amphiphilicity and

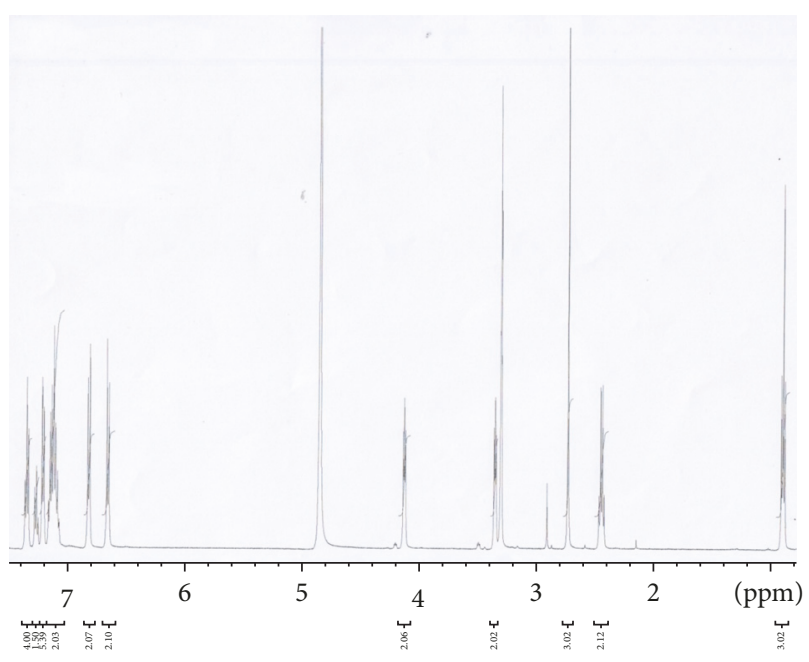

FIGURE 17: HNMR of N-desmethyltamoxifen.

TABLE 1: Tamoxifen content analysis of SWCNT-PEG-TAM.

\begin{tabular}{lc}
\hline & $\begin{array}{c}\text { Tamoxifen content }(\%) \\
(\text { mean } \pm S, n=3)\end{array}$ \\
\hline SWCNT-PEG-TAM & $67.18 \pm 1.27$ \\
\hline
\end{tabular}

TABLE 2: The concentration at which $50 \%$ cells survive.

\begin{tabular}{lc}
\hline Treatments & $\mathrm{CC}_{50}(\mu \mathrm{g} / \mathrm{ml})$ \\
\hline SWCNT-PEG & $>100^{\mathrm{a}}$ \\
Tamoxifen & $12.67 \pm 2.69^{\mathrm{b}}$ \\
SWCNT-PEG-TAM & $5.49 \pm 1.34^{\mathrm{c}}$ \\
\hline
\end{tabular}

$\mathrm{CC}_{50}$ : cytotoxic concentration; data with different superscript letters are significantly different $(p<0.05)$.

conformation of the functionalized SWCNT which may enhance cell wall penetration as compared to free hydrophobic tamoxifen. Based on the results of cell viability assay (Figure 19), the distinct concentrations of $25 \mu \mathrm{g} / \mathrm{ml}$ were selected for further investigations.

3.9. Microscopic Screening for Morphological Alterations. The microscopic screening for morphological alterations in the cells upon $24 \mathrm{~h}$ exposure to the $25 \mu \mathrm{g} / \mathrm{ml}$ of SWCNT-PEG, tamoxifen, and SWCNT-PEG-TAM is presented in Figure 20. The cells treated with SWCNT-PEG grew, spread well, and adhered firmly, while cells treated with a concentration of $25 \mu \mathrm{g} / \mathrm{ml}$ of tamoxifen and SWCNT-PEG-TAM underwent distinct morphological changes and alteration in the cell shape and morphology. It seemed that more round cells, detached cells, and floating cells together with apoptotic bodies were observed in the cells treated with SWCNT-PEGTAM as compared to tamoxifen treated cells.

3.10. Caspase-3 Activity Assay. Figure 21 represents the caspase- 3 activity in breast cancer cells upon $24 \mathrm{~h}$ exposure 


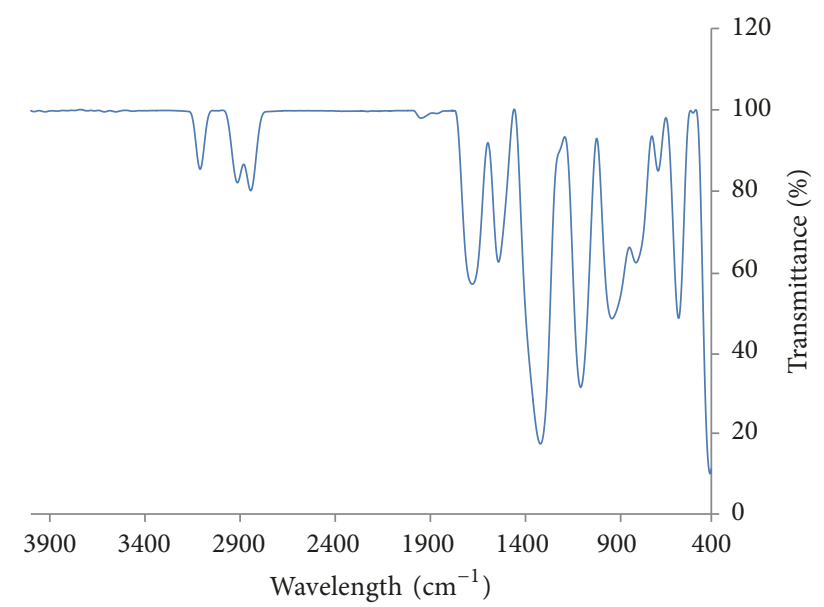

FIGURE 18: FT-IR data of chemical attachment of tamoxifen on modified SWCNT.
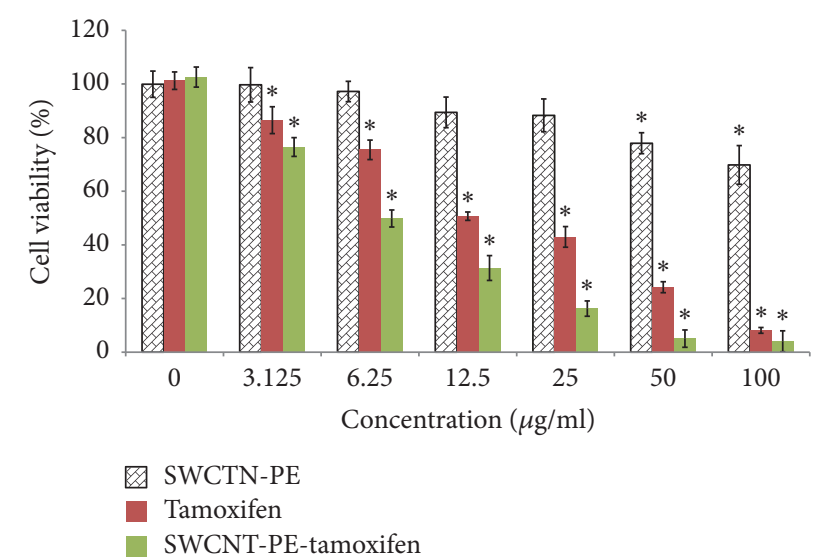

FIGURE 19: The effect of increasing concentrations of SWCNTPEG, tamoxifen, and SWCNT-PEG-TAM in human breast cancer cells (MCF-7 cell line) viability. The cells were treated for $24 \mathrm{~h}$ with different concentrations ranging from 0 to $100 \mu \mathrm{g} / \mathrm{ml}$. All values represent mean \pm standard error from three independent experiments. Bar chart with $*$ indicated significant difference $(p<$ $0.05)$ as compared to the control $(0 \mu \mathrm{g} / \mathrm{ml})$.

to $25 \mu \mathrm{g} / \mathrm{ml}$ of SWCNT-PEG, tamoxifen, and SWCNT-PEGTAM. The results revealed that tamoxifen and SWCNT-PEGTAM increased the caspase- 3 activity significantly $(p<0.05)$. In this study, the caspase- 3 activity was determined based on the hydrolysis of acetyl-Asp-Glu-Val-Asp p-nitroanilide (DEVD-p-NA) by caspase-3 resulting in the cleavage of chromophore p-nitroaniline moiety from labelled substrate DEVD-p-NA. The caspase-3 belongs to the executioner caspases which carries out the mass proteolysis that leads to apoptosis. The activation of caspase- 3 as a hallmark of apoptosis resulted in a range of substrates cleavage including downstream caspases, nuclear proteins, plasma membrane proteins, and mitochondrial proteins, finally leading to apoptotic cells death. Hence, the activation of caspase- 3 confirmed the presence of apoptotic cells death upon $24 \mathrm{~h}$ treatment with tamoxifen or SWCNT-PE-tamoxifen in the human breast cancer cells.

\section{Discussion}

The CNTs are applied in biomedical science for regeneration of nerve conduits, regeneration of bone, thermal treatment of cancer, and for the drug delivery purposes [25]. In the drug delivery, the synthesis and functionalization of CNTs are two important steps affecting the biocompatibility of carrier, efficacy, and delivery of anticancer drugs. Generally, the common methods for the synthesis of CNTs are including arc discharge [26], laser vaporization [27], and chemical vapor deposition (CVD) [28]. In this study, the SWCNT was successfully produced by CVD method. This result was in agreement with He et al. [29], who reported the CVD method as a promising strategy for production of high quality and high yield SWCNT.

The biocompatibility of SWCNTs for the drug delivery system is determined by the types of carbon source or the catalyst used in the synthesis process. The recent studies revealed that impurities like amorphous carbon or catalyst residue reduce the SWCNTs cellular biocompatibility [28, 30-32]. Treating CNTs with strong acid has also been shown to enhance the solubility and removal of metallic impurities and could cause the formation of $-\mathrm{COOH}$ groups on their surface which provided a platform for attachment of bioactive molecules [25]. In the current study, the results of Raman spectroscopy, SEM, and TEM revealed that purification technique removed the impurities and resulted in the production of high purity SWCNT. The early study conducted by Kam et al. [33] showed that the SWCNTs with high purity are able to enter the live cells by endocytosis without observable toxicity and they are synthetically steady in the biological environments. Generally, the SWCNTs are hydrophobic and disperse poorly in aqueous solution. However, the solubility of SWCNTs is enhanced through functionalization [5]. Overall, the functionalization and surface modification may improve the solubility, dispersion, biocompatibility, and stability of SWCNTs.

In this experiment for the functionalization of SWCNT, series processes such as oxidizing of SWCNT, attachment of polyethylene glycol to oxidized SWCNT, and attachment of azelaic acid to the polyethylene glycol group were performed and the results of FT-IR, HNMR, and CNMR confirmed the development of SWCNT with free functional carboxylic acid and hydroxyl groups. The functionalized SWCNT was further conjugated to an anticancer drug, tamoxifen. Similarly, an early study conducted by Madani et al. [25] showed that the functionalized CNTs using poly ethylene glycol (PEG) helped in the modification of CNTs surface with different functional groups such as terminal amine and carboxyl groups. These functional groups enhanced the dispersibility of the SWCNT in the aqueous phase, facilitated binding of an anticancer drug, such as tamoxifen, increased the circulation time, and enhanced permeability and retention effects in the tumor cells $[3,4]$.

Generally, the anticancer drugs could attach to the inner side and outside of the CNT structure. In this experiment, the tamoxifen molecules attached to the free hydroxyl and carboxyl groups present in the structure of functionalized 


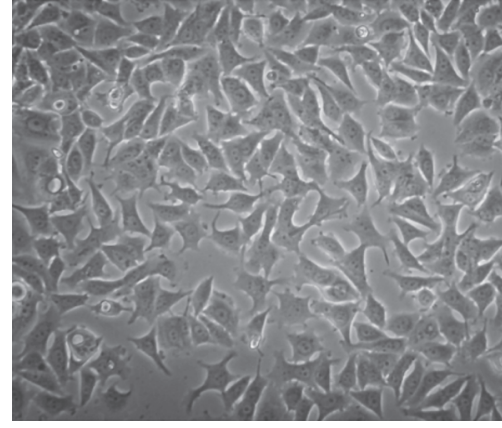

(a)

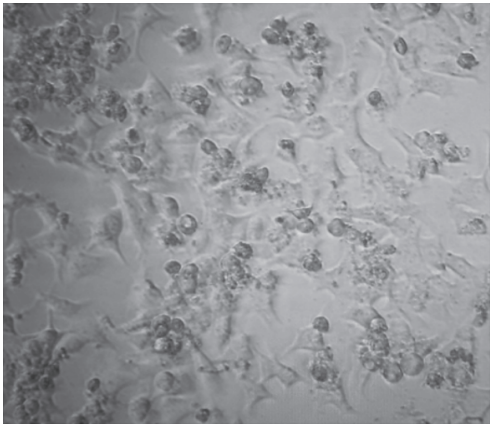

(b)

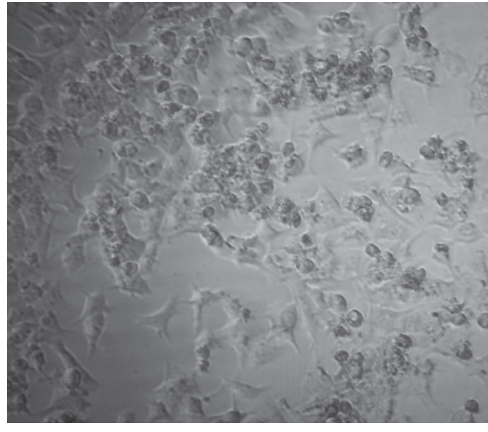

(c)

FIGURE 20: The morphological changes observed in human breast cancer cells (MCF-7) treated for $24 \mathrm{~h}$ with $25 \mu \mathrm{g} / \mathrm{ml}$ of (a) SWCNT-PEG, (b) tamoxifen, and (c) SWCNT-PEG-TAM examined by light microscopy at 200x magnification.

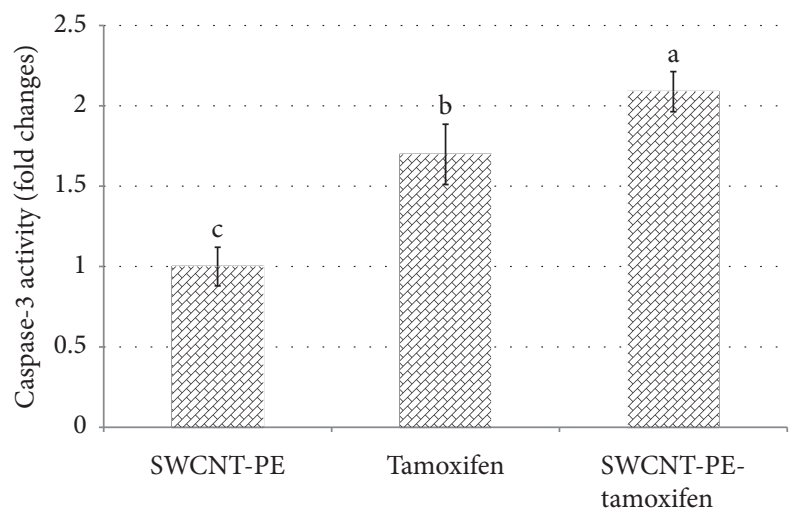

FIGURE 21: The caspase-3 activity in the breast cancer cells upon $24 \mathrm{~h}$ exposure to $25 \mu \mathrm{g} / \mathrm{ml}$ of SWCNT-PEG, tamoxifen, and SWCNTPEG-TAM. Bars with different letters are significantly different at $p<0.05$.

SWCNT. The analysis indicated that complex of SWCNT-PETAM contained $67 \%$ tamoxifen. This loading efficiency was higher than loading efficiency (32\%) reported by Tripisciano et al. [34] for multiwall carbon nanotube conjugated with irinotecan. However, the loading efficiency observed in this study was comparable with the result of Yang et al. [6] who reported the loading efficiency $62 \%$ for multiwall carbon nanotube containing gemcitabine as an anticancer drug.

The cell line studies are essential for characterization of anticancer drug delivery systems and could provide valuable information for predicting drug behavior in the in vivo cancer studies. Based on the results of cytotoxicity assay and morphological examination, the functionalized SWCNT is slightly toxic at the concentration of $50 \mu \mathrm{g} / \mathrm{ml}$ and above. In CNTs, the factors such as metal impurities, surface functionalization, and size and type of carbon nanotube could contribute to cytotoxicity of CNTs $[35,36]$. In this study, the cytotoxicity of SWCNT at the concentration of $50 \mu \mathrm{g} / \mathrm{ml}$ and above might not be due to the impurities (residual metal catalyst) as the SWCNT used in this study possessed the high purity. Thereby, the observed cytotoxicity could be attributed to the bioactivity of SWCNT. In line with these results, early researchers concluded that the physical properties of
SWCNT such as rigidity, surface area, and fiber length could determine the bioactivity of SWCNT [30, 32]. Although SWCNT showed slight toxicity in this study, this vehicle still could be promising for the delivery of the anticancer drug, tamoxifen. The tamoxifen which is known as a drug of choice for the breast cancer treatment actively inhibited the growth of cancer cells. Furthermore, the functionalized SWCNT conjugated with tamoxifen appeared to be more cytotoxic to the cancer cells as compared to the free tamoxifen. The higher cytotoxic effects of functionalized SWCNT-tamoxifen indicated that, to reach a similar effect of the drug, a much lower concentration of tamoxifen could be used. In fact, reducing the anticancer drug concentration is mandatory to reduce the toxic side effects of the drug to the healthy organs and tissues.

The results obtained from cytotoxicity assay were in agreement with the results of Sahoo et al. [37] who observed the cytotoxicity activity of camptothecin-poly vinyl alcohol(PVA-) CNT conjugate approximately 15 times higher than free camptothecin against human breast (MDA-MB-231) and skin (A-5RT3) cancer cell lines [37]. The other study conducted by Datir et al. [38] indicated that MWCNTshyaluronic acid conjugated to doxorubicin was efficiently internalized into human lung adenocarcinoma cells (A549 cells) through cellular endocytosis resulting in inducing 3.2 times higher cytotoxicity of the MWCNTs-hyaluronic aciddoxorubicin than free doxorubicin at the same concentration. The results obtained in this study suggested that functionalization of SWCNT could probably improve the uptake of tamoxifen in the breast cancer cells which might be due to the high aspect ratio and high surface area of the SWCNT.

The morphological examination together with the results of caspase- 3 activity confirmed the occurrence of apoptotic cells death in free tamoxifen and SWCNT-PE-tamoxifen treated cells. The higher caspase- 3 activity in the cells treated with SWCNT-PE-tamoxifen revealed the higher anticancer potential of conjugated tamoxifen as compared to the free tamoxifen. In line with this result, the poly ethylene glycolSWCNT loaded with paclitaxel appeared to be more effective in induction of apoptosis in the MCF-7 cell line as compared to the free paclitaxel [8]. Another study by Sahoo et al. [37] indicated that conjugation of camptothecin, an anticancer drug with low water solubility to CNT, enhanced the water 
solubility and subsequently efficacy of the drug in inducing apoptosis cells death in the breast and skin cancer cells. Thereby, in the current study, the conjugation of tamoxifen to SWCNT through branched polyethylene glycol chains probably improved the cellular uptake of tamoxifen through promoting cellular membrane perforation which resulted in increased apoptosis induction in the breast cancer cells. Although the mechanism of SWCNT penetration into cells was unclear, the needle-like shape of SWCNT may help passing cellular membrane or even cellular components without cell damage [3]. Most probably, in this study, the SWCNT facilitated the transportation of the tamoxifen across the cell membrane into the cells through enhancing drug solubility, cell membrane permeability, or activation of endocytosis. The earlier reports confirmed the reduced drug toxicity together with enhanced drug uptake by the tumor when SWCNTs were applied as drug carrier [7, 39, 40]. With regard to the great advantage of functionalized SWCNT for anticancer drug delivery and the results obtained in this study, the SWCNT-PEG-TAM could be a promising approach for human breast cancer therapy.

\section{Conclusions}

In this study, an anticancer drug delivery system based on functionalized SWCNT (SWCNT-PE) conjugated with tamoxifen (SWCNT-PEG-TAM) has been developed. The results obtained in this study revealed that this delivery system enhanced the therapeutic effects and anticancer potential of tamoxifen against human breast cancer cells. Therefore, the SWCNT-PE-TAM appeared to be a prospective drug delivery system for human breast cancer treatment. Further in vivo studies are now under investigation.

\section{Conflicts of Interest}

The authors declare that there are no conflicts of interest regarding the publication of this article.

\section{Authors' Contributions}

Arshin Oskoueian, Khamirul Amin Matori, Saadi Bayat, and Ehsan Oskoueian developed the conceptual framework and designed the experiments. Arshin Oskoueian, Saadi Bayat, and Ehsan Oskoueian contributed in conducting experiments and data collection and analysis. Arshin Oskoueian and Ehsan Oskoueian drafted the manuscript and Khamirul Amin Matori revised it. All authors read and approved the final manuscript.

\section{Acknowledgments}

The authors would like to acknowledge the financial support from the Malaysia Ministry of Higher Education (MOHE) through Research University Grant Scheme.

\section{References}

[1] L. A. Torre, R. L. Siegel, E. M. Ward, and A. Jemal, "Global cancer incidence and mortality rates and trends-an update," Cancer Epidemiology, Biomarkers \& Prevention, vol. 25, no. 1, pp. 16-27, 2016.

[2] D. J. Nelson, Shagufta, and R. Kumar, "Characterization of a tamoxifen-tethered single-walled carbon nanotube conjugate by using NMR spectroscopy," Analytical and Bioanalytical Chemistry, vol. 404, no. 3, pp. 771-776, 2012.

[3] A. Elhissi, W. Ahmed, V. R. Dhanak, and K. Subramani, "Carbon Nanotubes in Cancer Therapy and Drug Delivery," Emerging Nanotechnologies in Dentistry, pp. 347-363, 2012.

[4] Z. Sobhani, R. Dinarvand, F. Atyabi, M. Ghahremani, and M. Adeli, "Increased paclitaxel cytotoxicity against cancer cell lines using a novel functionalized carbon nanotube.," International Journal of Nanomedicine, vol. 6, pp. 705-719, 2011.

[5] M. Song, L. Zeng, S. Yuan, J. Yin, H. Wang, and G. Jiang, "Study of cytotoxic effects of single-walled carbon nanotubes functionalized with different chemical groups on human MCF7 cells," Chemosphere, vol. 92, no. 5, pp. 576-582, 2013.

[6] F. Yang, C. Jin, D. Yang et al., "Magnetic functionalised carbon nanotubes as drug vehicles for cancer lymph node metastasis treatment," European Journal of Cancer, vol. 47, no. 12, pp. 1873$1882,2011$.

[7] Z. Liu, K. Chen, C. Davis et al., "Drug delivery with carbon nanotubes for in vivo cancer treatment," Cancer Research, vol. 68, no. 16, pp. 6652-6660, 2008.

[8] C. L. Lay, H. Q. Liu, H. R. Tan, and Y. Liu, "Delivery of paclitaxel by physically loading onto poly(ethylene glycol) (PEG)graftcarbon nanotubes for potent cancer therapeutics," Nanotechnology, vol. 21, no. 6, Article ID 065101, 2010.

[9] E. C. Dreaden, S. C. Mwakwari, Q. H. Sodji, A. K. Oyelere, and M. A. El-Sayed, "Tamoxifen-poly(ethylene glycol)-thiol gold nanoparticle conjugates: Enhanced potency and selective delivery for breast cancer treatment," Bioconjugate Chemistry, vol. 20, no. 12, pp. 2247-2253, 2009.

[10] N. Zhao, C. He, J. Li, Z. Jiang, and Y. Li, "Study on purification and tip-opening of CNTs fabricated by CVD," Materials Research Bulletin, vol. 41, no. 12, pp. 2204-2209, 2006.

[11] S. Maruyama, R. Kojima, Y. Miyauchi, S. Chiashi, and M. Kohno, "Low-temperature synthesis of high-purity singlewalled carbon nanotubes from alcohol," Chemical Physics Letters, vol. 360, no. 3-4, pp. 229-234, 2002.

[12] A. Eatemadi, H. Daraee, H. Karimkhanloo et al., "Carbon nanotubes: Properties, synthesis, purification, and medical applications," Nanoscale Research Letters, vol. 9, no. 1, pp. 1-13, 2014.

[13] X. Liu, H. Bian, H. Zhou, L. Gao, S. Jiang, and Y. Zhang, "Effective purification of SWNTs based on combined method," Fullerenes, Nanotubes and Carbon Nanostructures, vol. 23, no. 1, pp. 78-82, 2015.

[14] S. C. Tsang, Y. K. Chen, P. J. F. Harris, and M. L. H. Green, "A simple chemical method of opening and filling carbon nanotubes," Nature, vol. 372, no. 6502, pp. 159-162, 1994.

[15] L. Dai, Intelligent macromolecules for smart devices: from materials synthesis to device applications, Springer Science Business Media, 2004

[16] P.-C. Ma, S.-Y. Mo, B.-Z. Tang, and J.-K. Kim, "Dispersion, interfacial interaction and re-agglomeration of functionalized carbon nanotubes in epoxy composites," Carbon, vol. 48 , no. 6 , pp. 1824-1834, 2010. 
[17] K. J. Kayser-Bricker, M. P. Glenn, S. H. Lee, S. M. Sebti, J. Q. Cheng, and A. D. Hamilton, "Non-peptidic substrate-mimetic inhibitors of Akt as potential anti-cancer agents," Bioorganic \& Medicinal Chemistry, vol. 17, no. 4, pp. 1764-1771, 2009.

[18] B. Sahana, K. Santra, S. Basu, and B. Mukherjee, "Development of biodegradable polymer based tamoxifen citrate loaded nanoparticles and effect of some manufacturing process parameters on them: a physicochemical and in-vitro evaluation," International Journal of Nanomedicine, vol. 5, no. 1, pp. 621-630, 2010.

[19] E. Oskoueian, N. Abdullah, S. Ahmad, W. Z. Saad, A. R. Omar, and Y. W. Ho, "Bioactive compounds and biological activities of Jatropha curcas L. kernel meal extract," International Journal of Molecular Sciences, vol. 12, no. 9, pp. 5955-5970, 2011.

[20] E. Oskoueian, N. Abdullah, Z. Idrus et al., "Palm kernel cake extract exerts hepatoprotective activity in heat-induced oxidative stress in chicken hepatocytes," BMC Complementary and Alternative Medicine, vol. 14, no. 1, article no. 368, 2014.

[21] B. Liu, C.-Y. Li, H.-J. Bian, M.-W. Min, L.-F. Chen, and J.-K. Bao, "Antiproliferative activity and apoptosis-inducing mechanism of Concanavalin A on human melanoma A375 cells," Archives of Biochemistry and Biophysics, vol. 482, no. 1-2, pp. 1-6, 2009.

[22] SAS, Statistical Analysis Institute (Version 9.1.3), SAS Institute Inc, Cary, NC, USA, 2003.

[23] C. O. Sim, M. R. Hamdan, Z. Ismail, and M. N. Ahmad, "Assessment of herbal medicines by chemometrics-assisted interpretation of FTIR spectra," Analytica Chimica Acta, pp. 1$14,2004$.

[24] Z. Wang, S. Sun, X. Li, Q. Zhou, L. Lin, and D. Du, "Direct determination of rhizoma cimicifuga by FTIR spectroscopy," Guang pu xue yu guang pu fen $x i=$ Guang pu, vol. 21, no. 3, pp. 311-313, 2001.

[25] S. Y. Madani, A. Tan, M. Dwek, and A. M. Seifalian, "Functionalization of single-walled carbon nanotubes and their binding to cancer cells," International Journal of Nanomedicine, vol. 7, pp. 905-914, 2012.

[26] E. Dervishi, Z. Li, Y. Xu et al., "Carbon nanotubes: Synthesis, properties, and applications," Particulate Science and Technology, vol. 27, no. 2, pp. 107-125, 2009.

[27] F. Kokai, I. Nozaki, T. Okada, A. Koshio, and T. Kuzumaki, "Efficient growth of multi-walled carbon nanotubes by continuouswave laser vaporization of graphite containing B4C," Carbon, vol. 49, no. 4, pp. 1173-1181, 2011.

[28] M. Kumar and Y. Ando, "Chemical vapor deposition of carbon nanotubes: a review on growth mechanism and mass production," Journal of Nanoscience and Nanotechnology, vol. 10, no. 6, pp. 3739-3758, 2010.

[29] C. He, N. Zhao, C. Shi, E. Liu, and J. Li, "Fabrication of nanocarbon composites using in situ chemical vapor deposition and their applications," Advanced Materials, vol. 27, no. 36, pp. 5422-5431, 2015.

[30] K. Fujita, M. Fukuda, S. Endoh et al., "Size effects of singlewalled carbon nanotubes on in vivo and in vitro pulmonary toxicity," Inhalation Toxicology, vol. 27, no. 4, pp. 207-223, 2015.

[31] H. Xiaoqing, "Single-walled carbon nanotubes induce fibrogenic effect by disturbing mitochondrial oxidative stress and activating NF- $\kappa \mathrm{b}$ signaling," Journal of Clinical Toxicology, no. 5, pp. 1-5, 2012.

[32] K. Fujita, M. Fukuda, S. Endoh et al., "Physical properties of single-wall carbon nanotubes in cell culture and their dispersal due to alveolar epithelial cell response," Toxicology Mechanisms and Methods, vol. 23, no. 8, pp. 598-609, 2013.
[33] N. W. S. Kam, T. C. Jessop, P. A. Wender, and H. Dai, "Nanotube molecular transporters: internalization of carbon nanotube-protein conjugates into mammalian cells," Journal of the American Chemical Society, vol. 126, no. 22, pp. 6850-6851, 2004.

[34] C. Tripisciano, M. H. Rümmeli, X. Chen, and E. BorowiakPalen, "Multi-wall carbon nanotubes - a vehicle for targeted Irinotecan drug delivery," Physica Status Solidi (b) - Basic Solid State Physics, vol. 247, no. 11-12, pp. 2673-2677, 2010.

[35] A. A. Shvedova, V. Castranova, E. R. Kisin et al., "Exposure to carbon nanotube material: assessment of nanotube cytotoxicity using human keratinocyte cells," Journal of Toxicology and Environmental Health, Part A. Current Issues, vol. 66, no. 20, pp. 1909-1926, 2003.

[36] K. Pulskamp, S. Diabaté, and H. F. Krug, “Carbon nanotubes show no sign of acute toxicity but induce intracellular reactive oxygen species in dependence on contaminants," Toxicology Letters, vol. 168, no. 1, pp. 58-74, 2007.

[37] N. G. Sahoo, H. Bao, Y. Pan et al., "Functionalized carbon nanomaterials as nanocarriers for loading and delivery of a poorly water-soluble anticancer drug: a comparative study," Chemical Communications, vol. 47, no. 18, pp. 5235-5237, 2011.

[38] S. R. Datir, M. Das, R. P. Singh, and S. Jain, "Hyaluronate tethered, "smart" multiwalled carbon nanotubes for tumortargeted delivery of doxorubicin," Bioconjugate Chemistry, vol. 23, no. 11, pp. 2201-2213, 2012.

[39] M. L. Schipper, N. Nakayama-Ratchford, C. R. Davis et al., "A pilot toxicology study of single-walled carbon nanotubes in a small sample of mice," Nature Nanotechnology, vol. 3, no. 4, pp. 216-221, 2008.

[40] A. Bianco, K. Kostarelos, and M. Prato, "Applications of carbon nanotubes in drug delivery," Current Opinion in Chemical Biology, vol. 9, no. 6, pp. 674-679, 2005. 


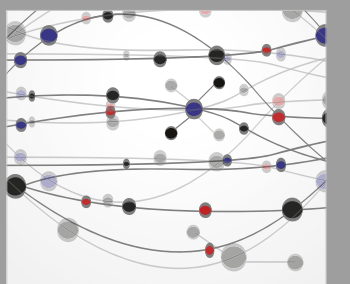

The Scientific World Journal
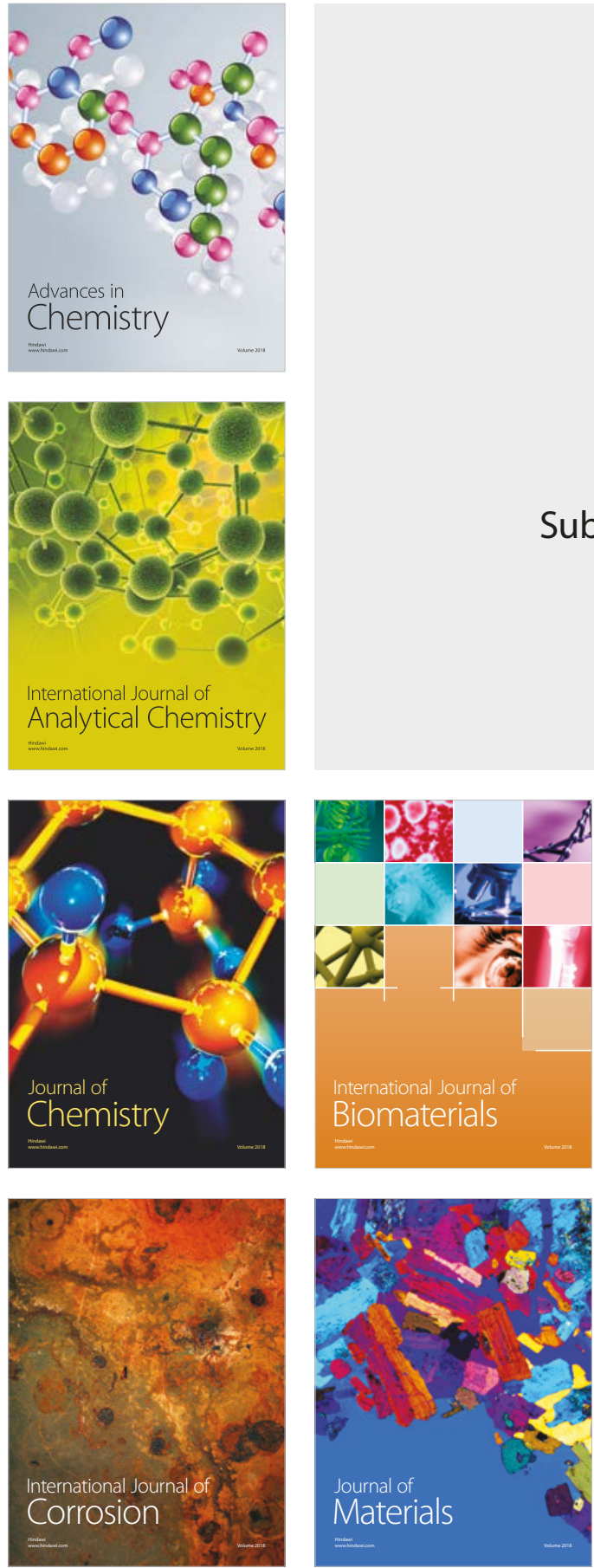

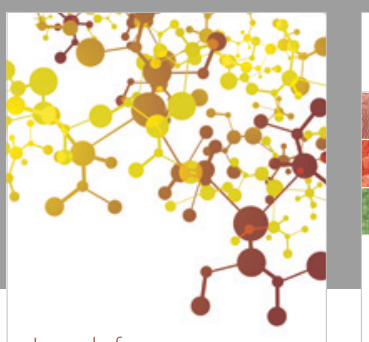

Journal of

Applied Chemistry
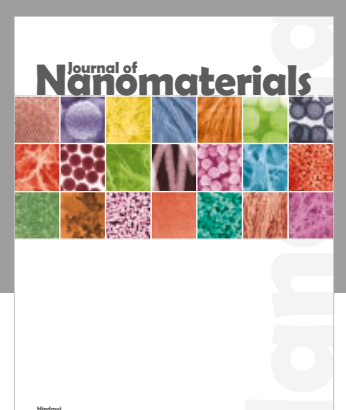

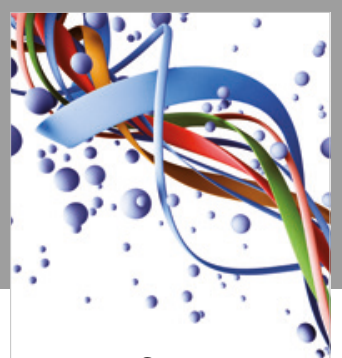

Scientifica

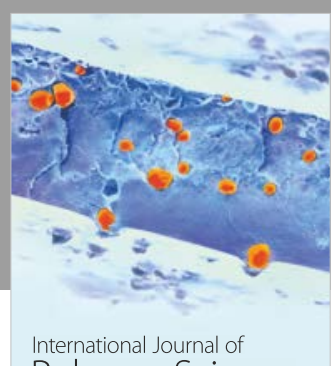

Polymer Science

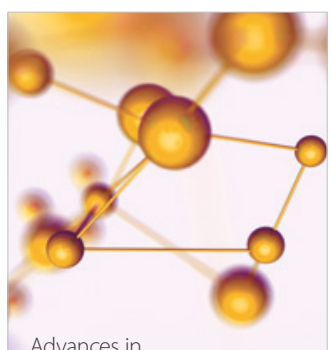

Physical Chemistry
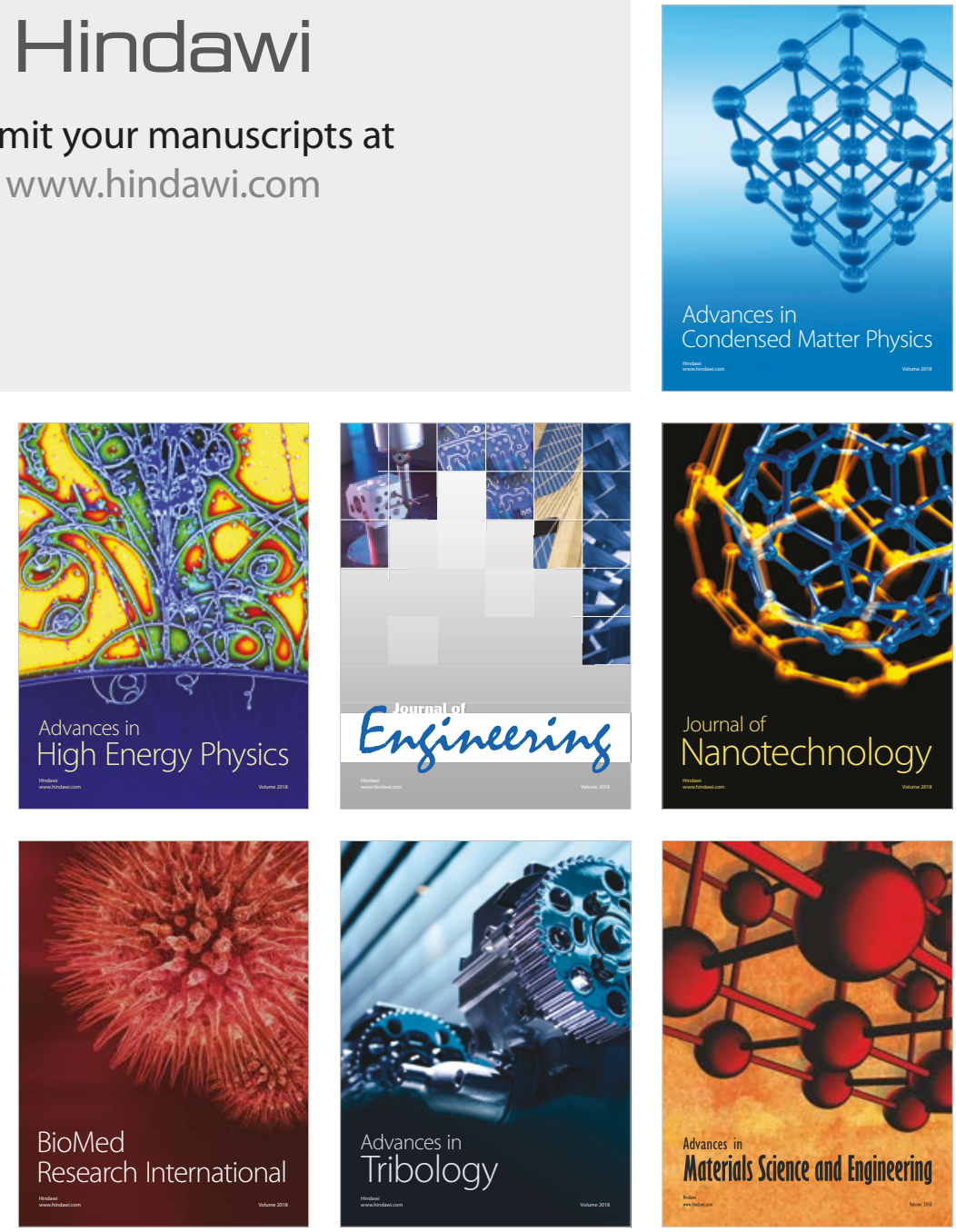